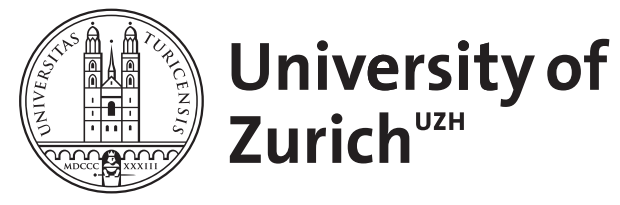

Zurich Open Repository and Archive

University of Zurich

University Library

Strickhofstrasse 39

CH-8057 Zurich

www.zora.uzh.ch

Year: 2013

\title{
Mittelmass statt Spitzenleistung
}

Neuner-Jehle, S

Posted at the Zurich Open Repository and Archive, University of Zurich ZORA URL: https://doi.org/10.5167/uzh-93674

Journal Article

Published Version

Originally published at:

Neuner-Jehle, S (2013). Mittelmass statt Spitzenleistung. PrimaryCare, 13(17):320. 


\title{
Mittelmass statt Spitzenleistung
}

\author{
Ein weiterer kaffeetischphilosophischer Mini-Essay
}

Citius, altius, fortius - schneller, höher, stärker ${ }^{1}$. Wir scheinen angetrieben zu sein, immer mehr Leistung zu bringen und besser als die anderen sein zu wollen. Im Sport ist es die Jagd nach Rekorden und Medaillen, in der Karriere kann keine Leiterstufe hoch genug sein, und die Spitzenlöhne der Topmanager sprechen für sich selbst. Spitzenmedizin wollen alle, und wenn die Kosten dafür ebenso extrem ausfallen, dann muss die Effizienz auf die Spitze getrieben werden, damit die Kosten wieder sinken.

Die anderen zu überflügeln, scheint uns in unser genetisches Programm eingebrannt zu sein; die Verhaltensbiologie spricht vom Drang zum Alphatier, auf dass die anderen beim Fressen und Fortpflanzen hinten anstehen. Und in der Literatur wimmelt es nur so von ehrgeizigen Helden, die meist früher oder später auf die Nase fallen (Ikarus) oder in der Absicht, über sich hinauszuwachsen, mit dem Feuer spielen (Faust).

Ist das wirklich gesund? Wohl kaum,

Haben Sie Mut zur

Mittelmässigkeit! denn die Cracks, die es an die Spitze schaffen, fahren oft physische und psychische Schäden ein: Leistungssportler, Spitzenpolitiker, charismatische Leader, die sich selbst ausbeuten. Und ist es wirklich gesund, beispielsweise ein Gesundheitswesen auf Spitzenleistung zu trimmen? Maximale Effizienz (die natürlich jederzeit belegt werden muss) eines bis ins Detail durchorganisierten Patientenpfades? Wo bleibt die (ineffiziente) Plauderei in der Sprechstunde, die nur Zeit kostet, kein Einkommen generiert und in keinem Qualitätsindikator aufscheint?
Wo bleibt der Genuss und die Gelassenheit, die Performance der anderen nicht jederzeit egalisieren oder übertrumpfen zu müssen? Wo die sympathische menschliche Schwäche? Fragen über Fragen, die bewährte Sprache der Philosophie ... Lassen Sie mich eine Hypothese wagen: Wenn wir alle uns mehr zum Mittelmass hin bewegten (nennen wir es in Analogie zu einem Phänomen der Statistik ${ }^{2}$ intention to the mean), wären wir alle gesünder. Oder immerhin entspannter. Wobei diese Intention keine faule Ausrede für Faulheit sein darf.

Gegenargument: Verzichten wir so nicht auf eine Triebfeder des Fortschritts? Wo wären wir mit unserer Medizin, wenn nicht selbstausbeutende Pioniere ihre Visionen getestet und gegen alle Widerstände publiziert hätten? Können wir auf solche Spitzenleistung wirklich verzichten? Brauchen wir nicht Herausforderungen, damit wir nicht in öder Langeweile durchs Leben dümpeln? Da haben wir den Salat: Kaum glaubt der Kaffeetischphilosoph, eine kleine Perle der Erkenntnis erhascht zu haben, tauchen schon wieder neue Fragen auf, die ihren Glanz verblassen lassen.

\section{Korrespondenz:}

Dr. med. Stefan Neuner-Jehle, MPH

Schmidgasse 8, 6300 Zug, sneuner[at]bluewin.ch

Das offizielle Motto der ersten Olympischen Spiele 1894. Ein weiteres, mehr inoffizielles kam erst später hinzu: «Das Wichtigste ist nicht zu gewinnen, sondern teilzunehmen.» Beide wurden vom gleichen Mann, Pierre de Coubertin, eingeführt.

Gemeint ist das Phänomen der regression to the mean.

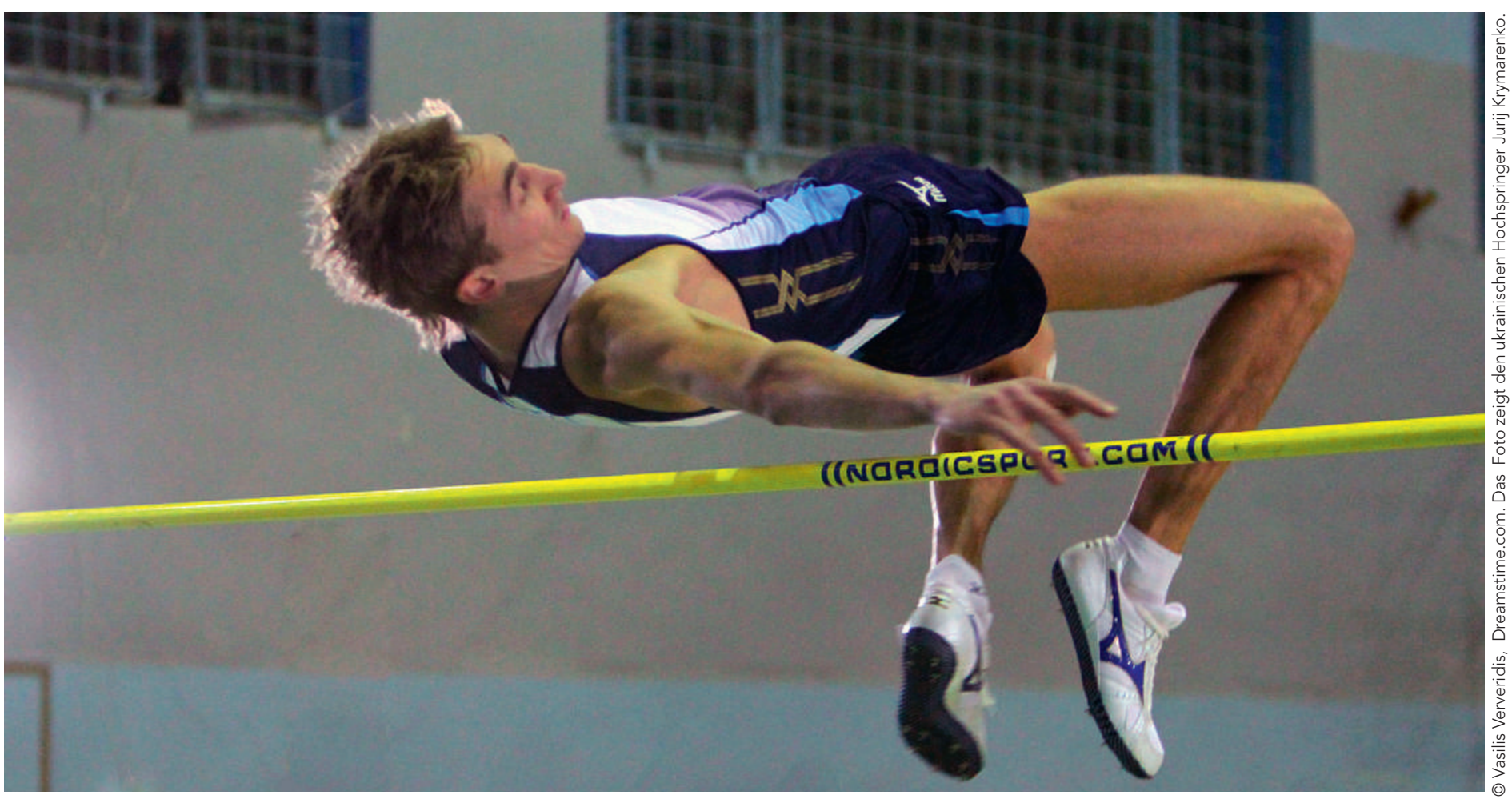

